\title{
Synthesis and Characterization of Citrus limonum Essential Oil Based Nanoemulsion and Its Enhanced Antioxidant Activity with Stability for Transdermal Application
}

\author{
Harleen Kaur ${ }^{1}$, Pranav Pancham², Ramneek Kaur³, Shriya Agarwal'2, Manisha Singh ${ }^{2 *}$ (i) \\ ${ }^{1}$ Amity Institute of Biotechnology, Amity University, Noida, U.P., India \\ ${ }^{2}$ Department of Biotechnology, Jaypee Institute of Information Technology (JIIT) Noida, U.P., India \\ ${ }^{3}$ School of Medicine, Western Sydney University, Campbelltown, New South Wales, Australia \\ Email: *manishasingh1295@gmail.com
}

How to cite this paper: Kaur, H., Pancham, P., Kaur, R., Agarwal, S. and Singh, M. (2020) Synthesis and Characterization of Citrus limonum Essential Oil Based Nanoemulsion and Its Enhanced Antioxidant Activity with Stability for Transdermal Application. Journal of Biomaterials and Nanobiotechnology, 11, 215-236.

https://doi.org/10.4236/jbnb.2020.114014

Received: July 9, 2020

Accepted: August 17, 2020

Published: August 20, 2020

Copyright $\odot 2020$ by author(s) and Scientific Research Publishing Inc. This work is licensed under the Creative Commons Attribution International License (CC BY 4.0).

http://creativecommons.org/licenses/by/4.0/

\begin{abstract}
Lemon oil (LO), also known as Citrus limonum is a highly volatile essential oil (EO) with potential therapeutic properties like anti-oxidative, anti-proliferative, anti-fungal and anti-cancerous. However, the efficacy of LO is limited due to its physiological factors such as high volatility, poor stability (particularly sensitive to sunlight) and quick degradability upon exposure. To overcome these challenges, we formulated lemon oil loaded nanoemulsion system (LO-NE) (oil-in-water), using aqueous titration method. The formulation comprised of lemon oil (LO), Tween 80 and ethanol as oil, surfactant and co-surfactant phases respectively. The existence zone of NE was established by constructing pseudo-ternary phase diagrams using different concentrations of LO, surfactant and co-surfactant $\left(\mathrm{S}_{\text {mix }}\right)$. The quantitative estimation of LO was performed using a high throughput gas chromatography, revealing the presence of various compounds like Limonene, Alpha-Pinene and Linalyl acetate followed by the estimation of total phenolics and flavonoid content. The characterization of LO-NE indicated the particle size of $60 \pm 2.5 \mathrm{~nm}$ along with the polydispersity index of 0.125 and zeta potential of $-14.9 \mathrm{mV}$. The size range of the NE particles dispersed in the colloidal system was further verified by TEM micrograph which shows size range between $46.2-104.7 \mathrm{~nm}$. All the anti-oxidant assays outcomes exhibited the higher activity of LO-NE in comparison to $\mathrm{LO}$ alone with lower $\mathrm{IC}_{50}$ values. The release kinetics statistical data showed that LO-NE had a sustained release and followed the Higuchi's model
\end{abstract}


in comparison to burst release of LO alone. Lastly, the stability analysis of the optimised formulation (LO-NE) and LO was estimated through antioxidant assay and subjecting them for thermodynamic stability after 6 months. The results attained, showed higher stability and anti-oxidant capability of LO-NE than LO alone. The study suggested that formulated nanoemulsion can be effectively used as a highly efficacious biologically active alternative nanoformulation against many transdermal disorders.

\section{Keywords}

Lemon Oil, Surfactants, Particle Size Analysis, Ternary Phase Diagrams, Release Kinetics, Thermodynamic Stability

\section{Introduction}

The therapeutic management of skin infections and disorders is one such continuous challenge globally that is not resolved completely until now and needs more targeted and efficacious drug delivery designs. In this context, the control or prevention of microbial infiltrations along with other skin disorders can be efficiently managed by the dual medicinal activity of the essential oils (EO). EO comprises of concentrated compounds extracted from leaves, twigs, fruits and roots of plants exhibiting many folds higher medicinal properties than the plant extracts or the pure compounds. They are commonly used in aromatherapy from last several decades and have a special mention in traditional medicinal practices where it is been equally used in cosmetics, therapeutics and even in spiritualism too. They are constituted by blends of ketones, aldehydes, oxides of terpenes, phenols, esters, alcohol and ethers which are associated in producing characteristic aroma and potential in alleviating stress; and augmenting attention, memory, sedation, arousal, sleep and immune system. Almost all the EOs are listed under the class of highly volatile compounds, exceptionally rich in secondary metabolites (terpenoids, flavonoids, nitrogen and sulphur containing alkaloids) [1]. Similarly, Citrus limonum (Lemon oil-LO), an EO with immense therapeutic benefits for dermal disorders is extracted from lemon peels of Rotacea through cold press extraction technique. It is composed of Limonene (up to $90 \%)$ and citral (3\% - 5\%); others are coumarins (bergamotine and limettine), and flavones (diosmine and limotricine) extensively used to treat cough, sprains, fungal infections, superficial wounds, etc. [2]. It exhibits important medicinal properties like anti-inflammatory, anti-nociceptive, anti-cancer, antioxidant, antifungal and antimutagenic. Also, citrus flavonoids are reported to be effective cytostatic anticancer agents [3] [4]. But despite of its potential therapeutic properties, its efficacy is restrained due to its physiological structural arrangements [5]. Further, it possesses very high content of hydrocarbons (terpenes-monoterpenes, diterpenes and sesquiterpenes), oxygenated compounds (alcohols and carbonyls) that makes it highly volatile and other phytoconstituents like 1 - 8 cineole are 
reported to cause severe inflammation, redness and itching, if applied directly [6]. Additionally, its stability in light and normal temperature is also questionable and causes dermatitis if there is exposure to sunlight after applying on skin [7]. Therefore, its direct application on skin is not recommended even after being an excellent choice for curbing infections. Pertaining to all the concerns listed and to improve the overall efficacy, bioavailability, residence time and stability of LO, an effective and stable nanocarrier system was required [8]. Since last few decades, various research works have displayed the evidences for NE system being the most suited carriers of active EOs. Also, they have been seen as the nanocarrier system with deeper penetration through the dermal layers, higher formulation stability, longer shelf life, enhanced drug solubility, and balanced $p \mathrm{H}$, making them most preferred choice in pharmaceutical industries for transdermal application. Furthermore, it was also reported that NE on conjugating with EO produces a synergistic effect and broad-spectrum biocidal activity which is far much higher than the EO itself. Hence, in the present study, we have fabricated a LO based oil-in-water (O/W) nanoemulsions (NE) system for enhanced therapeutic efficiency and stability of LO through transdermal route [9]. Here we have taken Citrus limonum pure EO as an oil phase, tween -80 as surfactant and ethanol as co surfactant to develop and optimise the NE formulation for transdermal application.

\section{Materials and Methodology}

Citrus limonum essential oil was provided by Aesthetic company, Saharanpur, Uttar Pradesh, India as a gift sample. 2, 2-diphenyl-1-picrylhydrazyl (DPPH), azino-bis reagent (3-ethylbenzothiazoline-6-sulfonic acid), Folin-Ciocalteu reagent, Griess reagent were obtained from Sigma Aldrich (USA). All other chemicals used were of analytical grade.

\subsection{Quantitative Analysis of Lemon Oil}

To determine the total quantity of phytochemicals (terpenes and oxygenated compounds) present in the LO, quantitative analysis was done using Gas chromatography-mass spectrometry (GC-MS). GC-MS was performed on Agilent Technology (Thailand) 6890 series gas chromatography (GC) system equipped with 5973 mass spectrometry (MS) detector and 7683 series auto-injector. The compounds were separated on HP5 column $(30 \mathrm{~m} \times 0.25 \mathrm{~mm}, 0.25 \mu \mathrm{m}$ filter). The column temperature was $70^{\circ} \mathrm{C}$ for $2 \mathrm{~min}$, and $130^{\circ} \mathrm{C}$ at $30^{\circ} \mathrm{C} / \mathrm{min}$ and changes the gradient to $230^{\circ} \mathrm{C}$ with $10^{\circ} \mathrm{C} / \mathrm{min}$ and held at $230^{\circ} \mathrm{C}$ for 6 min with the total run time of $20 \mathrm{~min}$. An electron ionization (EI) system with ionization energy $70 \mathrm{eV}$ was used for detection. The temperature of ion source was set at $230^{\circ} \mathrm{C}$, detector voltage was $2 \mathrm{kV}$ and the interface temperature were $250^{\circ} \mathrm{C}$. The mass spectrum was acquired in full scan mode at a rate of $0.98 \mathrm{scan} / \mathrm{sec}$ (mass range of $20-800 \mathrm{amu}$ ). The measurement was performed in duplicate for each sample with solvent delay for 2 min [10] [11]. 


\subsection{Fabrication and Optimization of LO-NE}

The fabrication and optimization of varied excipients in colloidal solution was performed by Spontaneous Emulsification method. For the preparation of LO-NE, LO was selected as an oil phase, Tween 80 and Ethanol as surfactant and co-surfactant, respectively with distilled water as an aqueous phase. Further, these excipients were blended together in 7 different $S_{\text {mix }}$ (surfactant and cosurfactant) ratios ranging from $1: 0$ to $1: 6$ and 16 varied combinations of oil: $S_{\text {mix }}(1: 9,1: 8,1: 7,1: 6,1: 5$ 1:4, 1:3.5, 1:3, 3:7, 1:2, 4:6, 5:5, 6:4, 7:3, 8:2, and 9:1) ratios. Thereafter, these prepared NE samples were kept on shaker at $37^{\circ} \mathrm{C}$ for 72 $\mathrm{h}$ to achieve equilibrium and then centrifuged at $2800 \mathrm{~g}$ for $15 \mathrm{~min}$ and analyzed for clear titration zones with no phase separation in the colloidal solution. Finally, the formulations were measured spectrophotometrically for the presence of flavonoid and phenolic content and the combinations ratios were plotted on ternary phase Triplot software [12] [13].

\subsection{Total Phenolic Content (TPC) Estimation}

Phenolics are considered amongst the class of most effective free radical scavengers that can interact with the biological systems and play role in anti-inflammatory, antimicrobial, anti-carcinogenic and antioxidant activities [14]. The TPC was performed by the Folin-Ciocalteu method with Gallic acid (GA) as a standard. Briefly, LO was dissolved in deionized water $(10 \% \mathrm{v} / \mathrm{v})$ and $0.5 \mathrm{~mL}$ of Folin-Ciocalteu $(1 \mathrm{~N})$ was added followed by vortexing and incubation for $5 \mathrm{~min}$ at $37^{\circ} \mathrm{C}$. Thereafter, $0.12 \mathrm{~mL}$ of $5 \%$ sodium bicarbonate was added to all the tubes and the reaction mixture was incubated for $40 \mathrm{~min}$ in dark, then absorbance was recorded at $725 \mathrm{~nm}$ subsequently. The mean of three replications were recorded and results were expressed as $\mathrm{mg}$ of Gallic acid equivalents (GAE) per $\mathrm{mL}$ of LO [15] [16].

\subsection{Total Flavonoid Content (TFC) Estimation}

Flavonoids are a strong antioxidant and show a radical scavenging activity and appear to lower the risk of chronic diseases. The TFC of LO was determined by aluminium chloride method against Quercetin standard $(1 \mathrm{mg} / \mathrm{mL})$. LO was dissolved in deionized water $(10 \% \mathrm{v} / \mathrm{v})$ followed by addition of $150 \mu \mathrm{L}$ of $5 \%$ sodium nitrite and the solution was vortexed for $5 \mathrm{~min} .150 \mu \mathrm{L}$ of $10 \%$ aluminum chloride was added and incubated for $5 \mathrm{~min}$. Lastly, $2 \mathrm{~mL}$ of $4 \%$ sodium hydroxide was added and absorbance was measured at $510 \mathrm{~nm}$. The samples were prepared in triplicate and the same procedure was repeated for the standard solution. The TFC was expressed as Quercetin equivalents in per $\mathrm{mL}$ of $\mathrm{LO}$ [17].

\subsection{Ternary Phase Studies}

Ternary Phase diagrams were constructed to study the interfacial tension between oil and water, stabilized by adding surfactant and co-surfactant in to the colloidal system. Pseudo-ternary phase diagrams of the prepared LO-NE with clear titration zones and different surfactant/cosurfactant ratios were plotted by 
using Triplot 4.1.2 software tool. Consequently, the existence zones representing the physical state of NE were determined by plotting the pseudo ternary phase diagram with three axis, one presenting the oil, another showing a constant $S_{\text {mix }}$ ratio and the third one representing the aqueous phase. It provides the insight into the behavior and compositional structure of the prepared NE system [18] [19].

\subsection{Thermodynamic Stability Studies}

The prepared NE formulations were analyzed for stability by subjecting them to varied alternative temperature and stress conditions. Firstly, they were incubated at $4^{\circ} \mathrm{C}$ for 3 days followed by $45^{\circ} \mathrm{C}$ for another 3 days, repeating the same cycle for 3 times. Thereafter, NEs were centrifuged at $2800 \mathrm{~g}$ for $30 \mathrm{~min}$ and the formulations that cleared the previous steps were exposed to freeze-thaw cycles by storing them at $-20^{\circ} \mathrm{C}$ ( 3 days) followed by $25^{\circ} \mathrm{C}$ ( 3 days). Lastly, all those NEs that sustained through all the tests were dispersed in water $(2 \mathrm{~mL})$ and checked for any creaming, coalescence and phase separations issues, if any. The ones that cleared all the tests and remained stable were further taken for characterization [20].

\subsection{Rheological Parameters}

The rheological parameters that were studied for the optimized formulation (LO-NE) included $p \mathrm{H}$, density, conductivity and viscosity. $p \mathrm{H}$ is the logarithmic concentration of hydrogen ion in the dispersed sample and the hydrogen bond interaction between the NE particles and their viscosity were found to be a key factor in influencing the process of agglomeration between them. The $p \mathrm{H}$ was measured using a $\mathrm{pH}$ meter (Thermo Orion, 420A+) and viscosity was determined by Brookfield viscometer. Similarly, electrical conductivity is known as a measure of electrical charge present on the dispersed particles in relation to dispersion medium, which was further analyzed by the conductometer (CM 180, Elico, India) at the frequency of $1 \mathrm{~Hz}[21]$.

\subsection{Characterization of Optimized LO-NE}

NE can be characterized by two ways-determination of physical properties (like shape, size, and dispersity) and chemical characteristics (like the presence of chemical bonding of ligands and other conjugated molecules, zeta potential). The techniques that were employed to characterize physical and chemical aspects of the NE were: Transmission electron microscopy, Particle size analysis; and Fourier transform infrared spectroscopy.

\subsubsection{Particle Size, Poly Dispersity Index and Zeta Potential Analysis}

Particle size analysis (PSA) is an integral tool for characterizing the size and homogeneity of the dispersed droplets in the NE. Likewise, Zeta potential (ZP) is a measure of effective electric charge present on the surface of the nanoformulation and quantifies the charge stability and degree of electrostatic repulsion between the particles in the colloidal solution. The average PSA and poly dispersity 
index (PDI) of LO-NE gives information about the size of the particle and their homogeneity was analyzed on a Photon Correlation Spectroscopy (Malvern Zetasizer $3000 \mathrm{HS}$ ) by diluting the test samples in ratio of 1:50 with water [23].

\subsubsection{Transmission Electron Microscopy (TEM)}

Transmission electron microscopy (TEM) is a high magnification measurement technique that images the transmission of electron beam through a sample. TEM is used to determine the morphological and structural framework of the colloidal suspension. The morphology of optimized NE was characterized by TEM analysis using TECHNAI $200 \mathrm{kV}$ TEM (Fei, Electron Optics) [24]. The sample was prepared by diluting 100 times with water and placing it on a copper TEM grid with LO-NE colloidal solution and 2\% Phosphotungstic acid. The slide was observed on an electron microscope [24] and staining it.

\subsubsection{Fourier Transform Infrared Spectroscopy (FTIR) Analysis}

The FTIR measurements were done to identify the functional groups present on the surface of LO and LO-NE nanoformulation (IR-810, JASCO, Tokyo) at Punjab University, Chandigarh, Punjab, India. The test samples (LO and LO-NE) were exposed to different wavelengths of IR spectra and the instrument measures the wavelengths that were absorbed. The samples were mixed with potassium bromide $(\mathrm{KBr})$ to make pellets for scanning in the copper grid and the frequency ranges were measured from wave numbers $400 \mathrm{~cm}^{-1}$ to $4000 \mathrm{~cm}^{-1}$ [25].

\subsection{In Vitro Antioxidant Assay}

\subsubsection{DPPH Assay}

The capacity of LO and LO-NE to donate hydrogen to reduce the 2,2-diphenyl1-picrylhydrazyl radical to 2,2-diphenyl-1-picrylhydrazyl helps to estimate the radical scavenging activity of the sample which is colorimetrically measured by observing the color change from purple to pale yellow color solution upon intensity of reaction [25]. Different concentrations of LO and LO-NE (2 - 10 $\mu \mathrm{l} / \mathrm{mL}$ ) were taken and $5 \mathrm{~mL}$ of $0.1 \mathrm{mM} \mathrm{DPPH}$ solution was added and incubated for $20 \mathrm{~min}$ at $27^{\circ} \mathrm{C}$. Absorbance was taken at $517 \mathrm{~nm}$ and ascorbic acid (AA) was used as a positive control. The minimum concentration of LO needed to scavenge $50 \%$ of DPPH solution (inhibitory concentration; IC50) was then further calculated from the plotted graph. The ability to scavenge DPPH was calculated using:

$$
\text { Scavenging activity }(\%)=\frac{I_{0}-I_{1}}{I_{0}} \times 100
$$

where, $I_{0}$ and $I_{1}$ are the absorbance of control and test samples, respectively [24] [25].

\subsubsection{ABTS Assay}

The reaction between ABTS reagent (2, 2'-azino-bis (3-ethylbenzothiazoline6-sulfonic acid) and potassium persulfate helps in direct formation of the ABTS radical of blue/green chromophore that plays a vital role in determining the sca- 
venging activity. Upon the addition of the sample, radical cation reduces the ABTS (de-colored solution) which is detected spectrophotometrically. Different concentrations of LO and LO-NE $(2-10 \mu \mathrm{l} / \mathrm{mL})$ were taken and $1 \mathrm{~mL}$ of ABTS solution $(7 \mathrm{mM})$ with $2.45 \mathrm{mM}$ potassium per-sulphate was added in these test samples followed by incubation of $12-16 \mathrm{~h}$ at $37^{\circ} \mathrm{C}$ and absorbance was measured at $734 \mathrm{~nm}$ [26]. AA was used as a positive control. Then, the concentration of LO sample required to scavenge $50 \%$ of ABTS solution $\left(\mathrm{IC}_{50}\right)$ was calculated from the graph. The ability to scavenge ABTS was calculated using:

$$
\text { inhibition }(\%)=\frac{I_{O}-I_{1}}{I_{O}} \times 100
$$

where, $I_{0}$ and $I_{1}$ are the absorbance of control and test samples, respectively [27].

\subsubsection{Hydrogen Peroxide Scavenging Assay}

Hydrogen peroxide $\left(\mathrm{H}_{2} \mathrm{O}_{2}\right)$ is a mild oxidant and is present in the phagosomes of the cells. Oxidation of $\mathrm{H}_{2} \mathrm{O}_{2}$ by phytocompounds decreases the absorbance which in turn helps in the estimation of the scavenging activity. Different concentrations of LO and LO-NE $(2-10 \mu \mathrm{l} / \mathrm{mL})$ were taken and $600 \mu \mathrm{L}$ of $\mathrm{H}_{2} \mathrm{O}_{2}(2 \mathrm{mM})$ was added [28]. The tubes were filled with phosphate buffers $(0.2 \mathrm{M}, p \mathrm{H}-7.4)$ to make up a constant volume of $0.4 \mathrm{~mL}$ and incubated for $10 \mathrm{~min}$ and the absorbance was measured at $230 \mathrm{~nm}$. The hydrogen peroxide scavenging activity of both the formulations was estimated and compared with AA which was a reference compound, by using the following equation:

$$
\mathrm{H}_{2} \mathrm{O}_{2} \text { activity }(\%)=\frac{I_{C}-I_{T}}{I_{C}} \times 100
$$

where, $I_{C}$ and $I_{T}$ are the absorbance of control and test samples, respectively [29].

\subsubsection{Superoxide Radical Scavenging Assay}

The assay is based on the ability to inhibit formazan formation by scavenging the superoxide radicals generated in riboflavin-light-NBT system. Different concentrations of LO and LO-NE $(2-10 \mu \mathrm{l} / \mathrm{mL})$ were taken followed by the addition of $3 \mathrm{~mL}$ of reaction mixture, consisted of $20 \mu \mathrm{g}$ riboflavin, $12 \mathrm{mM}$ EDTA and 0.1 mg Nitro blue tetrazolium (NBT) salt in $50 \mathrm{mM}$ sodium-phosphate buffer $(p \mathrm{H}$ 7.6) [30]. The tube was illuminated for $90 \mathrm{sec}$ and absorbance was measured at $590 \mathrm{~nm}$. Superoxide radical scavenging activity was calculated by-

$$
\text { Inhibition }(\%)=\frac{I_{C}-I_{T}}{I_{C}} \times 100
$$

where, $I_{C}$ and $I_{T}$ are the absorbance of control and test samples, respectively [31].

\subsection{In Vitro Release Kinetics}

In order to assess the release of LO from the prepared NE system, Franz diffusion cell facilitated release kinetics study was performed using pre-treated dialysis membrane (D9652, Sigma Aldrich, Singapore) and the receiver compartment was filled with phosphate buffer saline (PBS, $20 \mathrm{~mL}, p \mathrm{H}$ 7.4). The formulations 
were added through the donor membrane and $2 \mathrm{~mL}$ of test samples (LO and LO-NE) were taken out after every $30 \mathrm{~min}$ followed by addition of equal volume of PBS to maintain the equilibrium. The experiment was conducted for 12 hours and the measure of active phytoconstituents was done by GC-MS analysis as explained earlier [32].

\subsection{Stability Studies}

The stability of LO and LO-NE was tested by the method described by Basheer et al, 2013. Herein, we tested the stability of LO and LO-NE at the highest concentration $(10 \mu \mathrm{l} / \mathrm{mL})$ in terms of their ability to scavenge DPPH radical after storing the samples (LO, LO-NE) at $37^{\circ} \mathrm{C}$ for 6 months and then comparing with the fresh prepared samples [33] [34].

\subsection{Statistical Analysis}

All the data is expressed as mean \pm standard deviation and tested using one-way ANOVA. The values were considered significant at $\mathrm{p}<0.01$.

\section{Results and Discussion}

\subsection{Quantitative Analysis of Lemon Oil by GC-MS}

LO is known to possess a high content of terpenes including monoterpenes, diterpenes, sesquiterpenes and oxygenated compounds such as carbonyl, alcohols and phenols, all of them reported to be highly volatile of varied phytoconstituents. Therefore, to determine the total quantity present in the standard extract of LO A high throughput GC-MS method for EO analysis [35] was used. The predominant compound in LO was Limonene (Retention time, RT 17.66 $\mathrm{min}$ ), accounting for the peak area of $40.93 \%$ followed by Alpha-Pinene and $\mathrm{Li}$ nalyl acetate with the intensity of $29.24 \%$ (RT-12.98 $\mathrm{min}$ ) and $6.05 \%$ (RT-28.71 min) as represented in Figure 1. Table 1 summarizes the compound name, RT and chemical structures of all the identified compounds in LO found in this study.

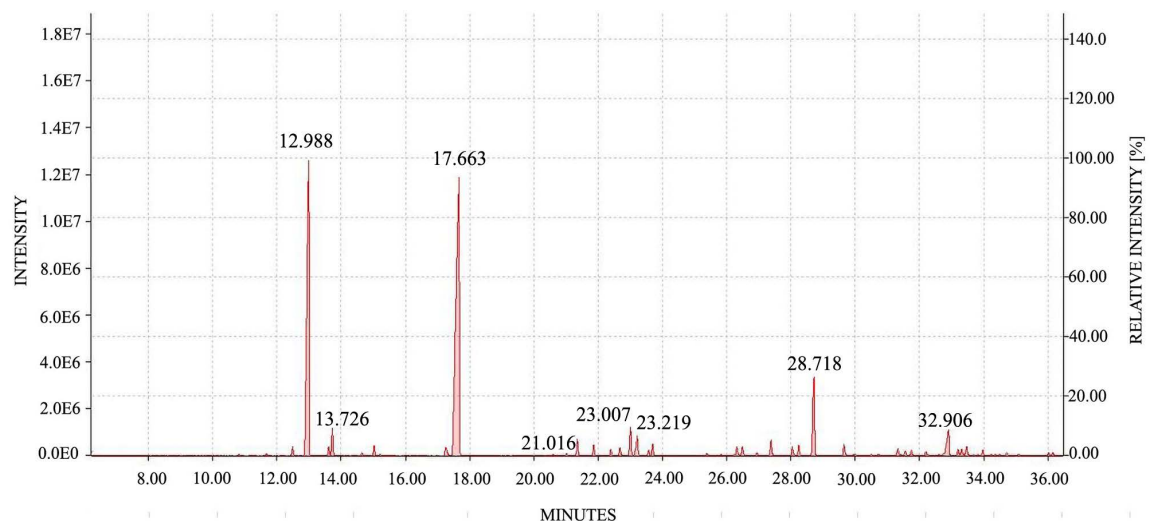

Figure 1. Representing the gas chromatography-mass spectrometry chromatogram of pure LO. 
Table 1. Summary of composition of LO.

\begin{tabular}{|c|c|c|c|}
\hline Compound identified & Chemical structure & Phytocompound & $\mathrm{RT}(\min )$ \\
\hline Alpha Pinene & & Terpene & 12.98 \\
\hline Camphene & & Bicyclic monoterpene & 13.72 \\
\hline D-Limonene & & Cyclic monoterpene & 17.66 \\
\hline Linalool & $\mathrm{CH}_{2}$ & Monoterpenoid & 21.01 \\
\hline Cis-Limonene Oxide & & Cyclic monoterpene & 23.00 \\
\hline Trans-Limonene Oxide & & Cyclic monoterpene & 23.21 \\
\hline Linalyl Acetate & & Acyclic monoterpenoid & 28.71 \\
\hline Triacetin & & Triglyceride & 32.90 \\
\hline
\end{tabular}

\subsection{Ternary Phase Studies}

Phase diagrams (Figures 2(a)-(e)) were constructed individually for varied $S_{\text {mix }}$ ratios (1:1, 1:2, 1:3, 1:4 and 1:5) to attain $\mathrm{O} / \mathrm{W}$ ME regions (Table 2). It was observed from the graphs that as the contents of surfactant were increased in the $S_{\text {mix }}$ ratio, there was the decline in isotropic region and it shifted more towards $S_{\text {mix }}$ axis (Figure 2). Further, this micelle behaviour and the degree of solubilisation of the optimised NE indicated the homogenous colloidal solution.

\subsection{Total Phenolic and Flavonoid Estimation}

The total phenolics content in LO was $70 \pm 2.5 \mathrm{GAE} / \mathrm{ml}$ of sample and $20 \pm 1.56$ $\mathrm{mg}$ Quercitin equivalent/mL of sample. 


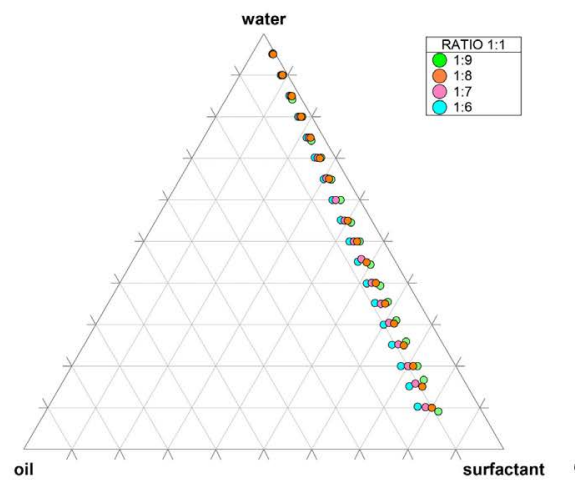

(a)

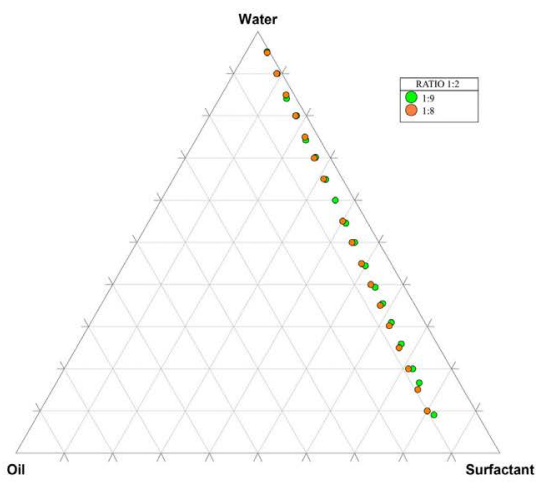

(b)

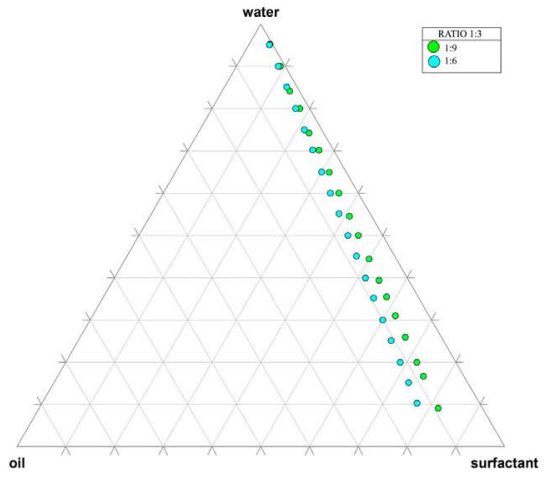

(c)

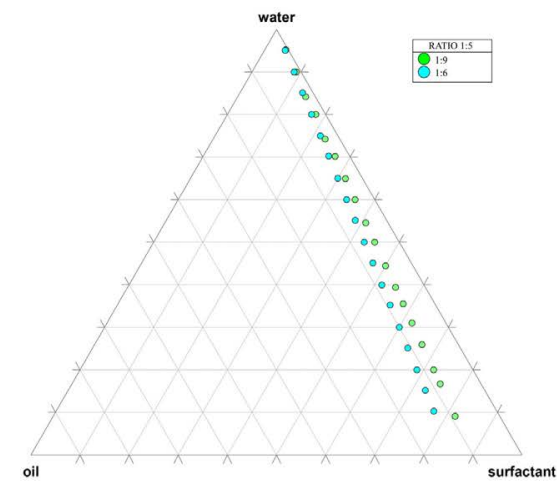

(d)

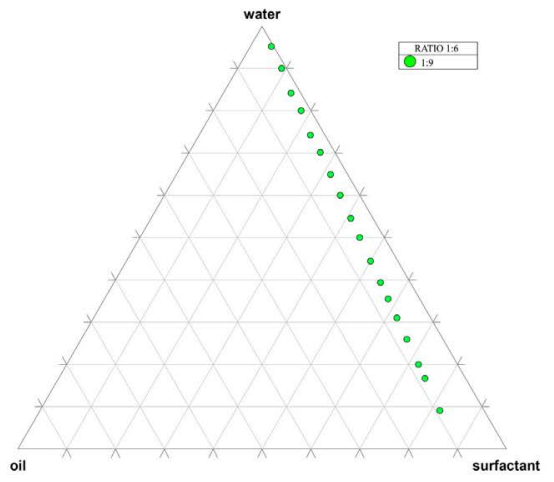

(e)

Figure 2. Pseudoternary phase diagrams indicating $\mathrm{O} / \mathrm{W}$ nanoemulsion using Lemon oil (Oil), tween 80 (surfactant) and ethanol (co-surfactant) using $S_{\text {mix }}$ ratio of (a) 1:1, (b) 1:2, (c) $1: 3$, (d) $1: 4$, (e) 1:5.

Table 2. Summary of various excipient combinations with their $S_{\text {mix }}$ ratios and attained clear titration ratios.

\begin{tabular}{cccc}
\hline S. No. & Combinations & S $_{\text {mix }}$ ratio & EO: S $_{\text {mix }}$ ratio \\
\hline 1 & LO + Tween 80 + Ethanol & $1: 1$ & $1: 9,1: 6,1: 7,1: 8$ \\
2 & LO + Tween 80 + Ethanol & $1: 2$ & $1: 9,1: 8$ \\
3 & LO + Tween 80 + Ethanol & $1: 3$ & $1: 9,1: 6$ \\
4 & LO + Tween 80 + Ethanol & $1: 4$ & $1: 9$ \\
5 & LO + Tween 80 + Ethanol & $1: 5$ & $1: 9,1: 6$ \\
6 & LO + Tween 80 + Ethanol & $1: 6$ & $1: 9$ \\
\hline
\end{tabular}




\subsection{Thermodynamic Stability Study}

The thermodynamic stability testing of all the five combinations of LO-NE was done to analyse their physiological stability [36]. They were subjected for heating-cooling cycle followed by centrifugation tests and then freeze thaw cycle, lastly dispersibility test and during the entire tenure of testing time the samples were checked for constantly any kind of creaming, cracking, coagulation, phase separation or turbidity issues [37] [38]. After completing all the cycles of thermodynamic stability testing the most suitable formulation preparation $\left(\mathrm{S}_{\text {mix }}\right.$ ratio: 1:1 and LO: $S_{\text {mix }}$ ratio: 1:9) was selected as final optimized formulation based on its visual inspection and categorization as grade "A". This selected formulation was then taken further for all other characterization tests to study more about its structural and biological properties [39].

\subsection{Rheological Parameters}

The $p \mathrm{H}$ for LO and LO-NE was found to be $3.5 \pm 0.5$ and $5.3 \pm 0.27$ respectively (Table 3), which suggested that the formulation is much more suitable for transdermal application and safe as per the prescribed GRAS (Generally Regarded as Safe) limits, avoiding skin irritation. Consequently, the density of LO (1.6 \pm 0.4 $\mathrm{g} / \mathrm{mL})$ was recorded slightly higher than LO-NE $(1.05 \pm 0.2 \mathrm{~g} / \mathrm{mL})$, much closer to the density of water $(1 \mathrm{~g} / \mathrm{ml})$ making it safe and suitable to impregnate the dermal layers and reach much deeper layers through transcellular route. Then the conductivity of LO-NE $(452.8 \pm 0.6 \mathrm{mS} / \mathrm{cm})$ was found to be closer to the conductivity of deionized water, sustaining an ideal action potential inside the biological system and enhancing the permeation of LO-NE. Lastly, the viscosity of LO-NE was observed to be $35 \pm 0.2 \mathrm{cps}$ regarded as safe for dermal usage [40] [41].

\subsection{Characterization of LO-NE}

\subsubsection{Particle Size, Poly Dispersity Index and Zeta Potential Analysis}

The PSA results obtained for LO-NE was found to be $59.06 \pm 1.16 \mathrm{~nm}$ with PDI score of 0.125 (Figure 3) exhibiting homogenous colloidal solution with NE particles existing in less than $100 \mathrm{~nm}$ range enabling the smoother transition of LO-NE delivery through dermal routes. ZP measures to be $-14.9 \mathrm{mV}$ suggesting that there is higher degree of stability in the electro-kinetic effect and surface charge present on the particle [42].

\subsubsection{Transmission Electron Microscopy}

The TEM micrograph showed the uniformly distributed spherical structure morphology of the optimized nanoparticles (LO-NE) with the size range of 46.2 - $104.7 \mathrm{~nm}$ which is in accordance with the average particle size of $60 \pm 2.5 \mathrm{~nm}$ obtained from zeta sizer (Figure 4).

Table 3. Rheological parameters of LO and LO-NE.

\begin{tabular}{ccccc}
\hline Sample & $p \mathrm{H}$ & Density $(\mathrm{g} / \mathrm{ml})$ & Conductivity $(\mathrm{mS} / \mathrm{cm})$ & Viscosity $(\mathrm{cP})$ \\
\hline LO & $3.5 \pm 0.5$ & $1.6 \pm 0.4$ & $440 \pm 0.4$ & $50 \pm 0.6$ \\
LO-NE & $5.3 \pm 0.27$ & $1.05 \pm 0.2$ & $452.8 \pm 0.6$ & $35 \pm 0.2$ \\
\hline
\end{tabular}




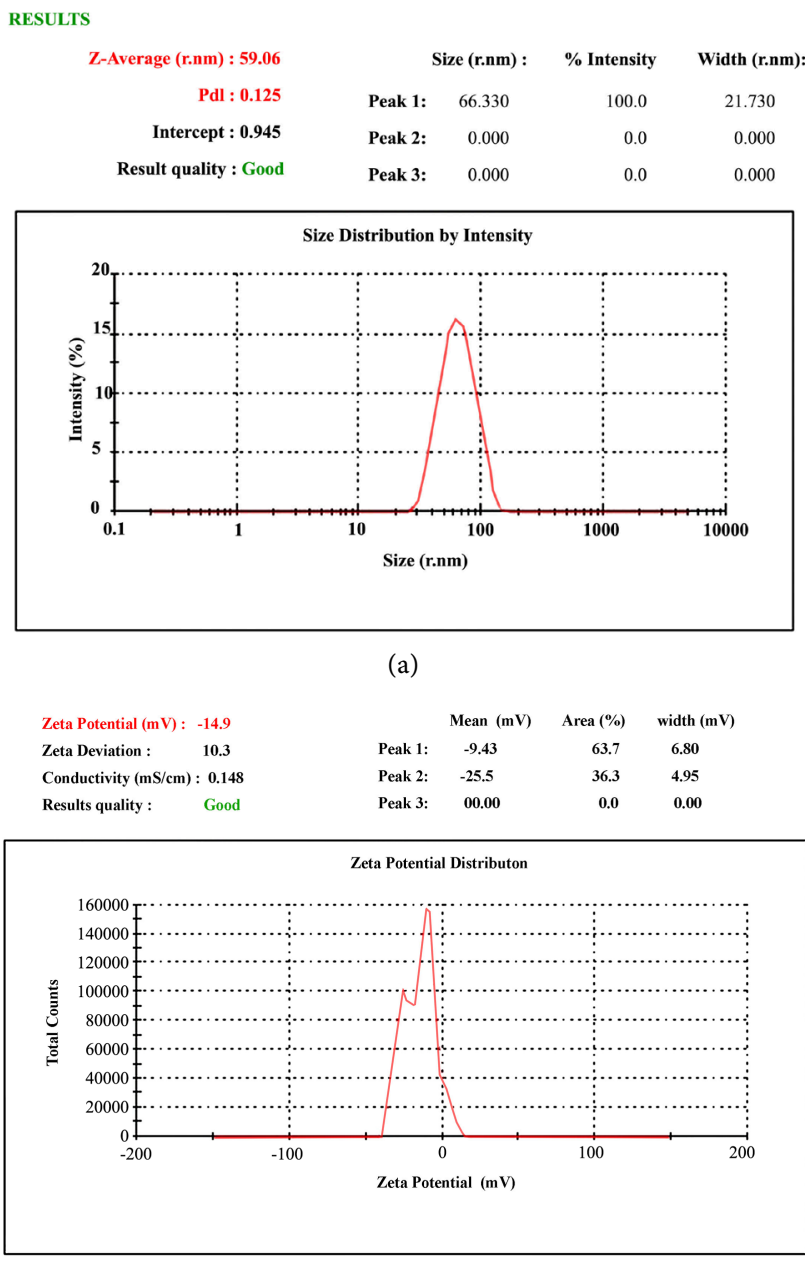

(b)

Figure 3. (a) Particle size analysis and (b) zeta potential of the optimized LO-NE.

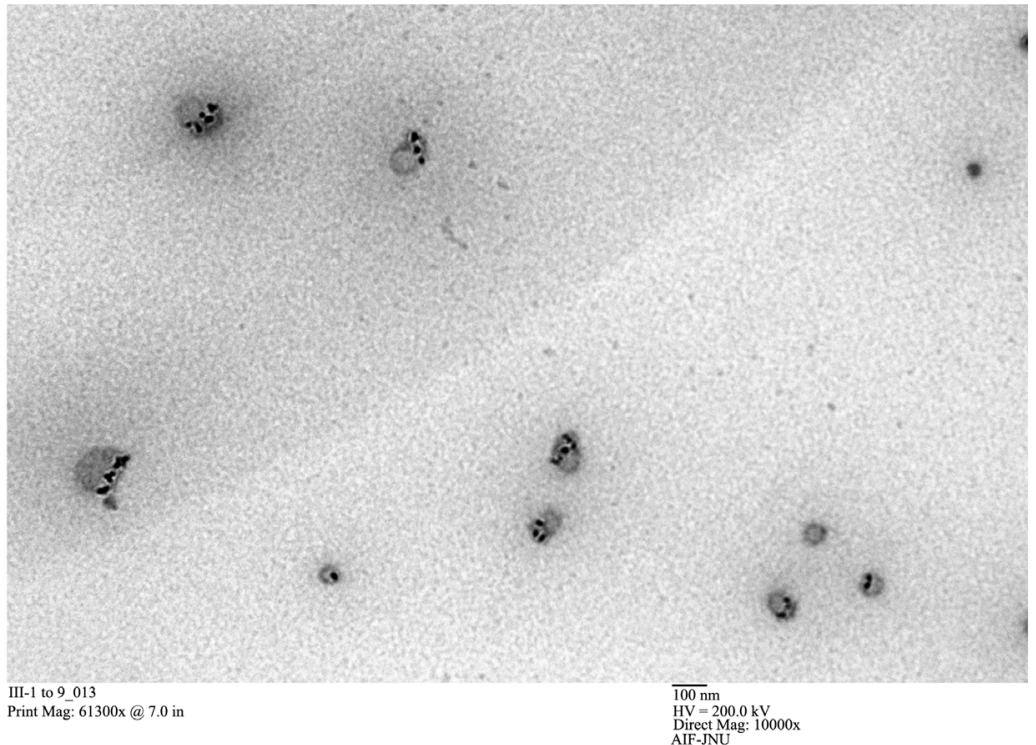

Figure 4. Micrograph showing Transmission Electron Microscopy (TEM) analysis of LO-NE at $100 \mathrm{~nm}$ magnification. 


\subsubsection{Fourier-Transform Infrared Spectroscopy (FTIR)}

The FTIR peaks of LO and LO-NE consists of Linalool, D-Limonene, Triacetin, $\alpha$-Pinene and trans-Limonene corresponding to $\mathrm{O}-\mathrm{H}$ stretch, $\mathrm{C}-\mathrm{H}$ stretch, $\mathrm{C}=\mathrm{O}$ stretch, C=C stretch and C-O stretch at $3441 \mathrm{~cm}^{-1}, 2915 \mathrm{~cm}^{-1}, 1745 \mathrm{~cm}^{-1}, 1645$ $\mathrm{cm}^{-1}$ and $1218 \mathrm{~cm}^{-1}$ respectively. The $\mathrm{O}-\mathrm{H}$ stretch of Linalool shows a strong and broad peak in the range of $3550-3200 \mathrm{~cm}^{-1}$, whereas LO-NE revealed the same peak at $3367 \mathrm{~cm}^{-1}$. The peak shift towards lower wavenumber can be attributed to increased mass of molecule. The mass of vibrating molecule is inversely proportional to the frequency of vibration as higher the mass of the molecule, less will be the vibration frequency and lower will be its wavenumber. Similarly, this pattern was observed in C-H stretch of D-Limonene in the range of 3333 - 3267 $\mathrm{cm}^{-1}$, the peaks appeared to be strong and sharp and in case of LO-NE this stretch was observed in increased wavenumber $2921 \mathrm{~cm}^{-1}$. The $\mathrm{C}=\mathrm{O}$ stretch of Triacetin in LO was observed with a strong peak in range of $1750-1735 \mathrm{~cm}^{-1}$ and LO-NE exhibited same peak at $1725 \mathrm{~cm}^{-1}$. Furthermore, $\mathrm{C}=\mathrm{C}$ stretch of $\alpha$-Pinene and C-O stretch of trans-Limonene was seen at $1650-1638 \mathrm{~cm}^{-1}$ and $1310-1250 \mathrm{~cm}^{-1}$ corresponding to LO-NE at $1649 \mathrm{~cm}^{-1}$ and $1253 \mathrm{~cm}^{-1}$. Therefore, we conclude that all the characteristic peak of LO-NE and LO followed the same path [43] [44] (see Figure 5).

\subsection{In Vitro Antioxidant Assay}

DPPH analysis is considered as one of the accurate methods for the antioxidant evaluation. This assay depicts the stable radical scavenging rate of DPPH by the presence of antioxidative compounds in the LO-NE. The $\mathrm{IC}_{50}$ value is the measure of the potency of a substance in inhibiting the scavenging activity by $50 \%$. LO-NE showed $\mathrm{IC}_{50}$ of $4.74 \pm 0.93 \mu \mathrm{l} / \mathrm{mL}$ whereas for $\mathrm{LO}$ it was $5.98 \pm 0.65$ $\mu \mathrm{l} / \mathrm{mL}$ (Table 4). This clearly indicated that the LO-NE has higher ability to scavenge the free radicals present at a lower concentration in comparison to LO alone. The maximum antioxidative ability was observed at a concentration of 10 $\mu \mathrm{l} / \mathrm{mL}$ where the corresponding activity was $93 \% \pm 0.91 \%$ in LO-NE which was much more than the LO $(75.99 \% \pm 0.91 \%)$ (Figure 6(a)). Therefore, the order for inhibition was in the following order: LO-NE > LO > control. Similarly, in case of ABTS, the antioxidant activity increased with increase in the concentration of test samples. For LO-NE the scavenging was $97.66 \% \pm 1.02 \%$ whereas, for LO, it was $81.36 \% \pm 1.92 \%$ at $10 \mu \mathrm{l} / \mathrm{mL}$ (Figure $6(\mathrm{~b})$ ). Furthermore, the $\mathrm{IC}_{50}$ value was $4.53 \pm 0.59 \mu \mathrm{l} / \mathrm{mL}$ in case of LO-NE and $6.51 \pm 0.52 \mu \mathrm{l} / \mathrm{mL}$ for LO. This proved that LO-NE exhibited higher scavenging ability than LO and control. Among all the reactive oxygen species present, hydrogen peroxide is the most reactive one which has the ability to generate the radical molecule during a reaction. LO-NE has the ability to scavenge out $\mathrm{OH}^{-}$free radicals in a dose dependent manner. The highest activity of scavenging was observed at a concentration of $10 \mu \mathrm{l} / \mathrm{mL}$ which corresponded to $88.72 \% \pm 1.09 \%$ and $92 \pm 1.25$ from Hydrogen peroxide and Superoxide radical scavenging assays, respectively (Figure 6(c) 
and Figure 6(d)). Therefore, from all the antioxidant assay conducted we can conclude that the LO-NE possess higher free radical scavenging activity when compared to that of LO [45] [46].

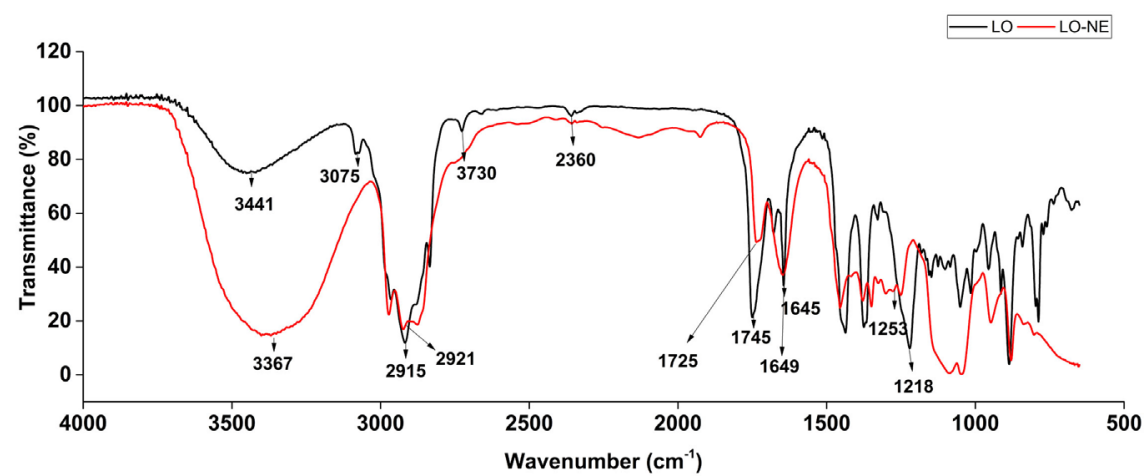

Figure 5. Graphical representation of FTIR results of LO and LO-NE.

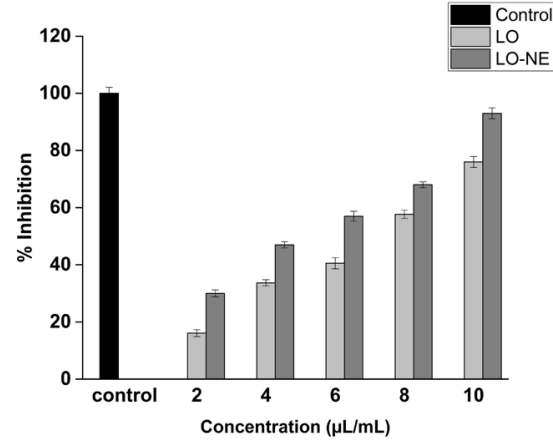

(a)

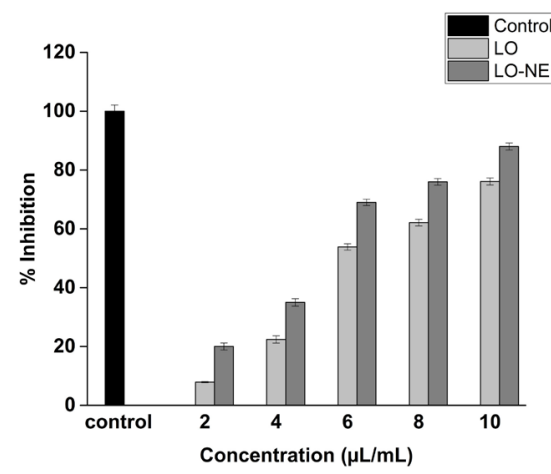

(c)

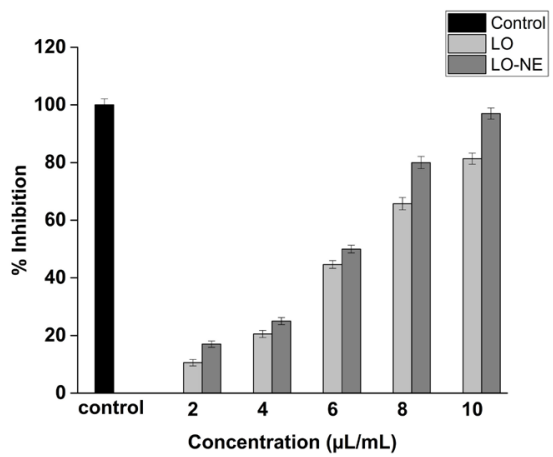

(b)

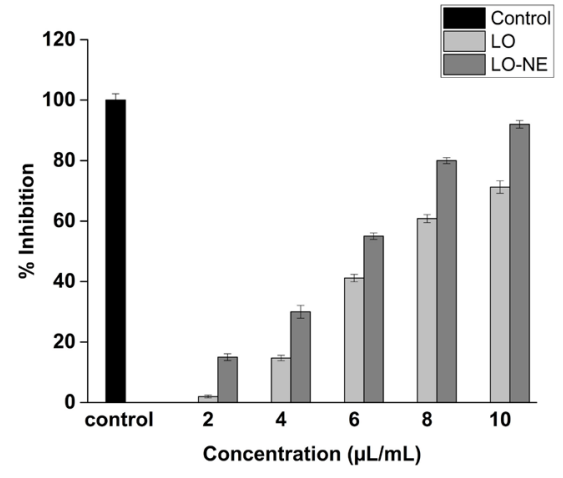

(d)

Figure 6. Graph depicting (a) DPPH; (b) ABTS; (c) Hydrogen peroxide; (d) Superoxide radical scavenging activity (\%) of LO, LO-NE at different concentrations $(2-10 \mu \mathrm{l} / \mathrm{mL})$.

Table 4. IC $\mathrm{C}_{50}$ Values of the LO and LO-NE in ABTS and DPPH assay.

\begin{tabular}{ccc}
\hline Assay & IC $_{50}$ of LO $(\mu \mathrm{l} / \mathrm{mL})$ & IC $_{50}$ of LO-NE $(\mu \mathrm{l} / \mathrm{mL})$ \\
\hline ABTS assay & $6.51 \pm 0.52$ & $4.53 \pm 0.59$ \\
DPPH assay & $5.98 \pm 0.65$ & $4.74 \pm 0.93$ \\
\hline
\end{tabular}




\subsection{In Vitro Release Kinetics}

The Franz diffusion setup for evaluating compound release kinetics was run for 12 hours and the readings were recorded at the interval of every hour. The pattern of compound release showed that $80 \%$ of the drug was released in initial 6 hours and only $20 \%$ was released in the second half of the experiment. The graph of percentage cumulative compound release versus time can be studied to validate the sustained release of the compound with time (Figure 7). The pattern of release for LO and LO-NE evidently showed the improvement in release profile of $\mathrm{LO}$ in the form of NE in contrast to the pure extract form. The analysis of data and verification from the standard release kinetics models (Figure 8) exhibits that the data best fits with Higuchi's model, giving the highest value for correlation coefficient $\left(\mathrm{R}^{2}=0.9812\right.$ for LO-NE) (Table 5). The Higuchi's model for release kinetics analysis is considered as the most well-known equation for controlled release [47] [48].

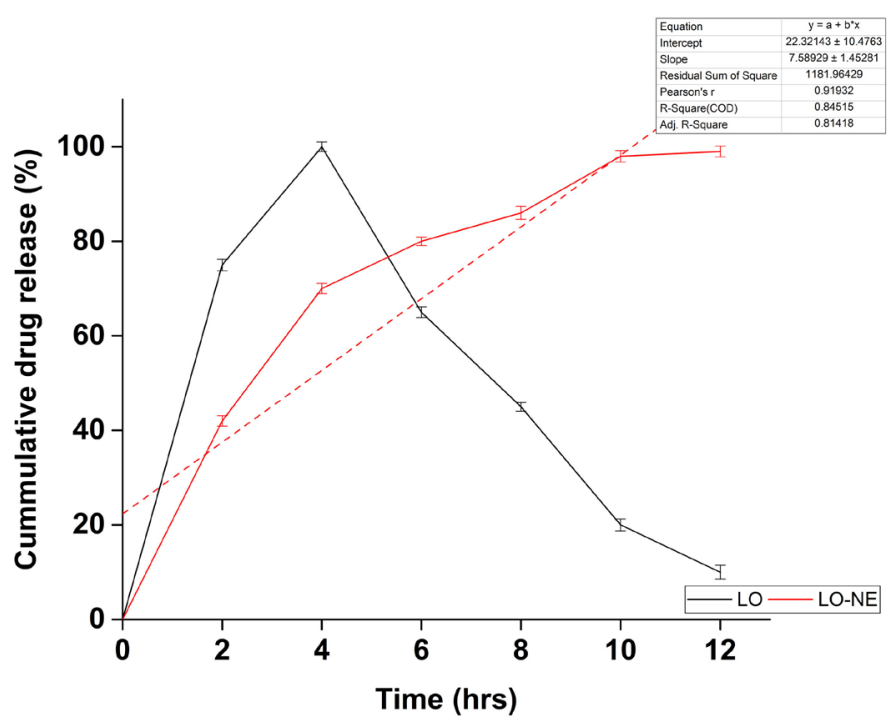

Figure 7. Comparative analysis of drug release in LO and LO-NE.

Table 5. Kinetic modelling of LO and LO-NE.

\begin{tabular}{cccc}
\hline Formulation & Kinetic model & Equation & $\mathbf{R}^{2}$ \\
\hline \multirow{3}{*}{ LO-NE } & Zero order & $\mathrm{y}=7.58 \mathrm{x}+22.32$ & 0.845 \\
& First order & $\mathrm{y}=-0.16 \mathrm{x}+2.13$ & 0.933 \\
& Higuchi's model & $\mathrm{y}=29.72 \mathrm{x}+2.81$ & 0.981 \\
& Hixson Crowell's model & $\mathrm{y}=0.30 \mathrm{x}+0.122$ & 0.978 \\
& Korsemeyer Peppas model & $\mathrm{y}=89.16 \mathrm{x}+8.45$ & 0.979 \\
\hline \multirow{2}{*}{ LO } & Zero order & $\mathrm{Y}=-2.41 \mathrm{x}+59.46$ & 0.079 \\
& First order & $\mathrm{Y}=0.082 \mathrm{x}+0.725$ & 0.0613 \\
& Higuchi's model & $\mathrm{Y}=0.131 \mathrm{x}+44.71$ & $2 \mathrm{E}-05$ \\
& Hixson Crowell's model & $\mathrm{Y}=-0.104 \mathrm{x}+1.89$ & 0.0876 \\
& Korsemeyer Peppas model & $\mathrm{Y}=-5.433 \mathrm{x}+48.61$ & 0.0034 \\
\hline
\end{tabular}




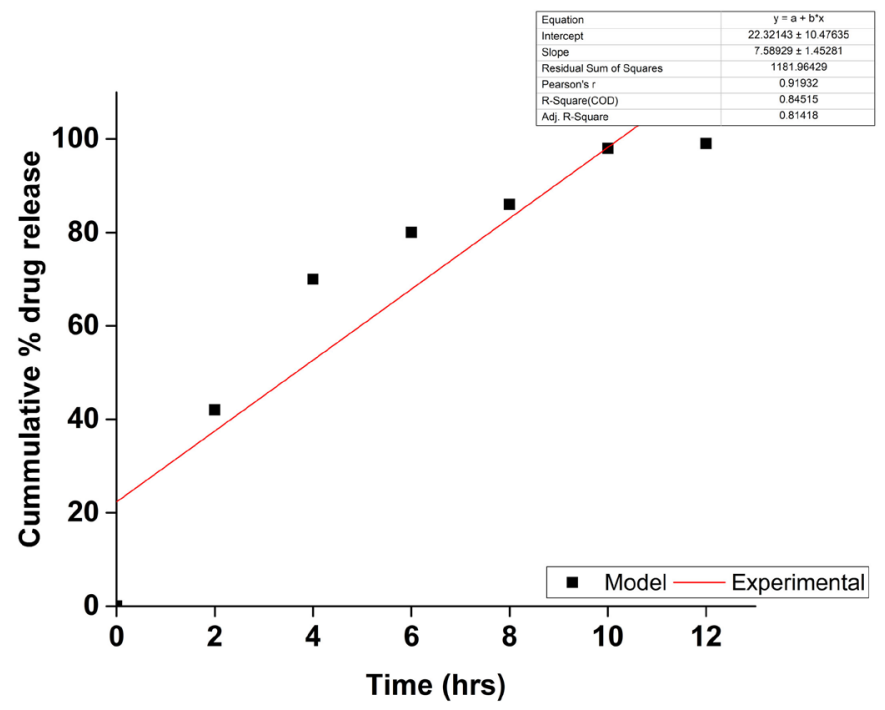

(a)

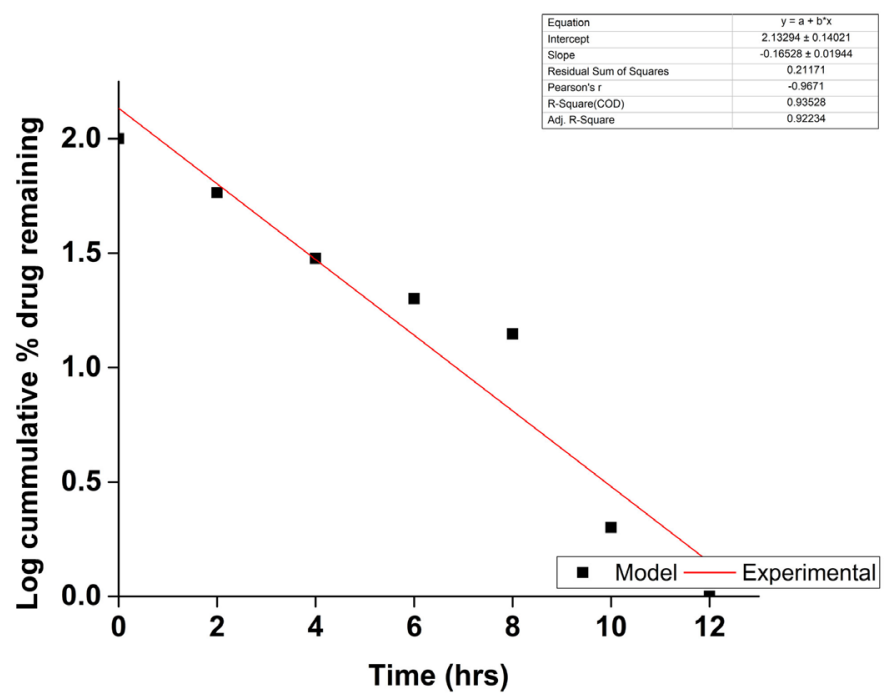

(b)

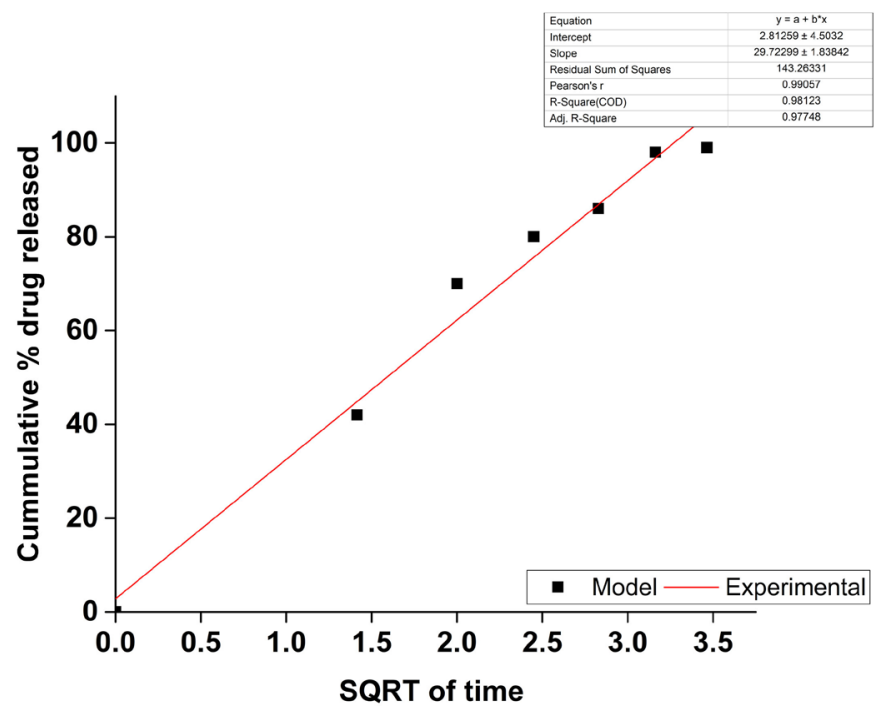

(c) 


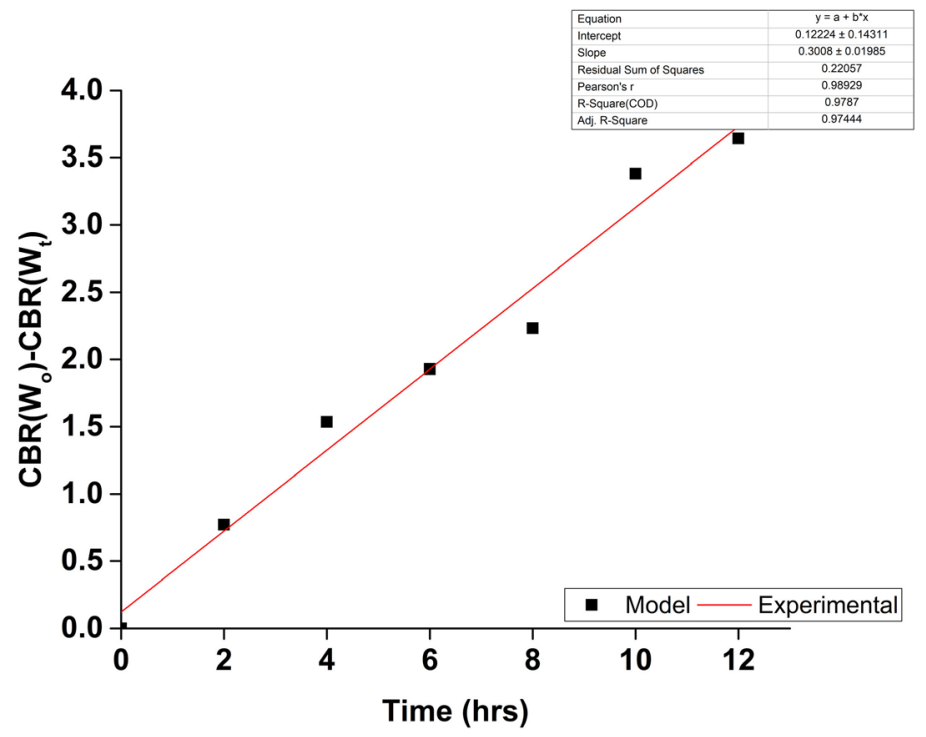

(d)

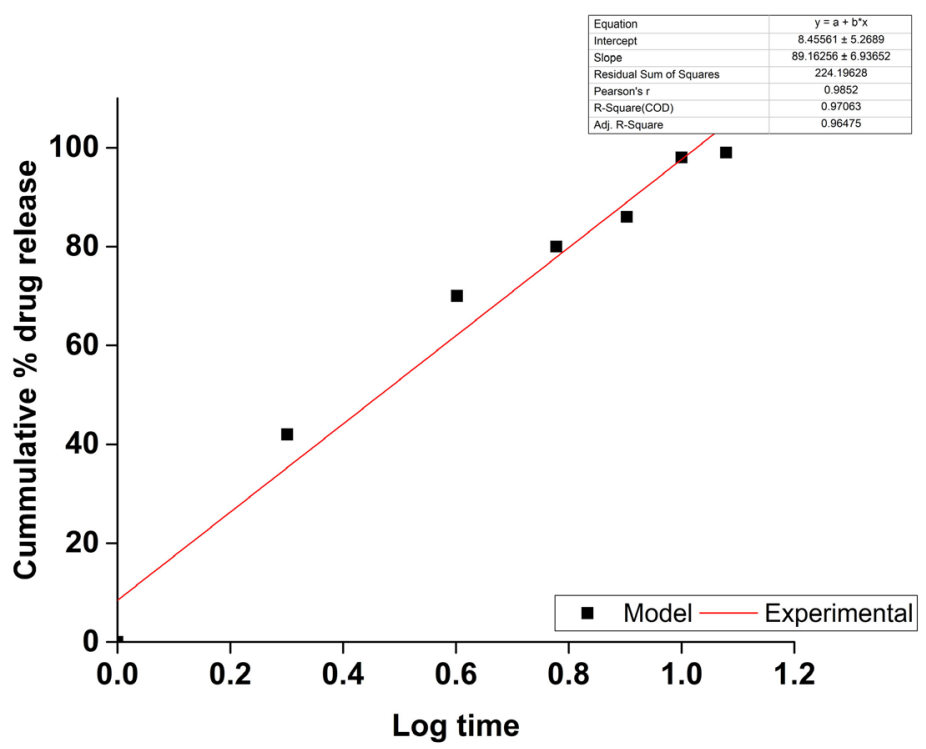

(e)

Figure 8. Kinetic drug release analysis of LO-NE using (a) Zero order; (b) First order; (c) Higuchi's; (d) Hixson Crowell's and (e) Korsemeyer Peppas model.

\subsection{Stability Studies}

In the current study the stability of the LO-NE, LO was tested in terms of antioxidant activity after 6 months at $517 \mathrm{~nm}$ by DPPH assay. LO-NE was found to be stable in comparison to $\mathrm{LO}$ at the temperature of $37^{\circ} \mathrm{C}$ (Figure 9). For the 10 $\mu \mathrm{l} / \mathrm{mL} \mathrm{LO}$, the antioxidant activity was $75.99 \pm 1.97 \%$ which degraded within the span of 6 months and reduced to $60 \pm 2.54 \%$ which can be attributed to the volatile nature of LO. On the contrary, the antioxidant activity of LO-NE was estimated to be $93 \pm 1.51 \%$ initially which after 6 months with a minor degradation reduced to $85 \pm 1.61 \%$. Therefore, the results suggested that, the LO-NE have higher stability percentage index than that of the pure LO alone [49]. 


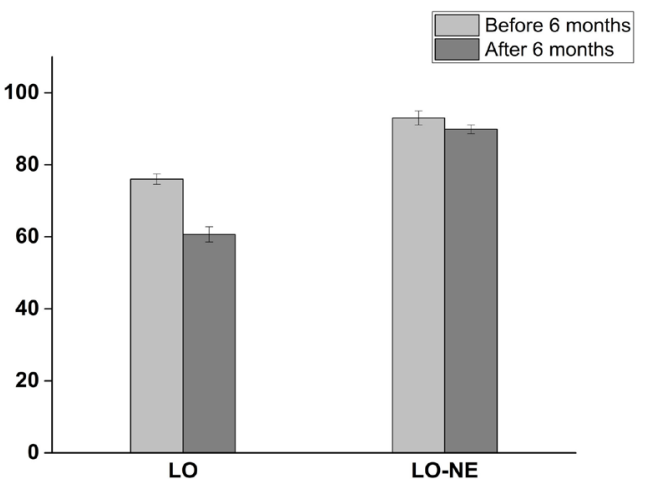

Figure 9. Stability of LO and LO-NE after 6 months using DPPH assay at $10 \mu \mathrm{l} / \mathrm{mL}$.

\section{Conclusion}

In the present study, pertaining to all the concerns regarding the volatility and stability of LO was addressed. For this LO based nano sized, biodegradable carrier system with higher therapeutic index and shelf life was successfully designed. The GC-MS analysis results identified several phytochemicals such as Limonene, Alpha-Pinene, Linalyl acetate. Meanwhile total phenolic and flavonoids were estimated as $70 \pm 2.5 \mathrm{GAE} / \mathrm{mL}$ and $20 \pm 1.56 \mathrm{mg}$ quercetin equivalent $/ \mathrm{mL}$ of sample respectively for LO. Further, the antioxidant assays such as ABTS, DPPH, $\mathrm{H}_{2} \mathrm{O}_{2}$ and Superoxide Radical Scavenging activity assays showed a higher scavenging activity percentage for LO-NE in comparison to LO and control; and lower $\mathrm{IC}_{50}$ for LO-NE. Hence, suggesting that NE system has reduced the biochemical degradation, limited the volatilization of LO components thus, improving the bioavailability of phytocompounds and also allowing the controlled drug release. Furthermore, all the recorded physicochemical parameters were in suitable range to facilitate the transportation of LO-NE across the deeper dermal layers. FTIR scans of LO and LO-NE reflected various types of peaks, stretching and functional group presence within the particular range with carbon stretching and maximum of alkyl and alkane group present with no changes in compound properties, concluding to the fact that the properties of lemon oil were not changed. Thus, on the basis of attained results data it can be well stated that this formulation (LO-NE) can prove out to be a vital replacement as natural therapeutic medicine for transdermal application.

\section{Conflicts of Interest}

The authors declare no conflicts of interest regarding the publication of this paper.

\section{References}

[1] Ahmed, J., Ahamad, T., Alhokbany, N., Almaswari, B.M., Ahmad, T., Hussain, A., Al-Farraj, E.S. and Alshehri, S.M. (2018) Molten Salts Derived Copper Tungstate Nanoparticles as Bifunctional Electro-Catalysts for Electrolysis of Water and Supercapacitor Applications. ChemElectroChem, 5, 3938-3945.

https://doi.org/10.1002/celc.201801196 
[2] Ahn, S.I., Chogsom, C., Lee, Y.K., Kwak, H.S. and Chang, Y.H. (2019) Optimization of the Conditions for Producing Water-in-Oil-in-Water Microemulsions and Spray-Dried Microcapsule of Tomato Extract Powder. Food Science and Technology, 39, 202-210. https://doi.org/10.1590/fst.42017

[3] Bora, H., Kamle, M., Mahato, D.K., Tiwari, P. and Kumar, P. (2020) Citrus Essential Oils (CEOs) and Their Applications in Food: An Overview. Plants, 9, 357. https://doi.org/10.3390/plants9030357

[4] Mathew, B.B., Jatawa, S.K. and Tiwari, A. (2012) Phytochemical Analysis of Citrus limonum Pulp and Peel. International Journal of Pharmacy and Pharmaceutical Sciences, 4, 369-371.

[5] Mohanapriya, M., Ramaswamy, L. and Rajendran, R. (2013) Health and Medicinal Properties of Lemon (Citrus limonum). International Journal of Ayurvedic and Herbal Medicine, 3, 1095-1100.

[6] Bertuzzi, G., Tirillini, B., Angelini, P. and Venanzoni, R. (2013) Antioxidative Action of Citrus limonum Essential Oil on Skin. European Journal of Medicinal Plants, 3, 1-9. https://doi.org/10.9734/EJMP/2013/1987

[7] Bhalla, Y., Gupta, V.K. and Jaitak, V. (2013) Anticancer Activity of Essential Oils: A Review. Journal of the Science of Food and Agriculture, 93, 3643-3653. https://doi.org/10.1002/jsfa.6267

[8] Peng, Y., Yin, L. and Li, Y. (2013) Combined Effects of Lemon Essential Oil and Surfactants on Physical and Structural Properties of Chitosan Films. International Journal of Food Science \& Technology, 48, 44-50. https://doi.org/10.1111/j.1365-2621.2012.03155.x

[9] Onyeyirichi, I., Ogechi, N., Oche, O., Jerry, U. and Gero, M. (2014) Evaluation of Chemical Constituent of Citrus medica Limonum Leaf Essential Oil. Journal of Pharmaceutical and Scientific Innovation, 3, 306-309. https://doi.org/10.7897/2277-4572.034161

[10] Alfonzo, A., Martorana, A., Guarrasi, V., Barbera, M., Gaglio, R., Santulli, A., Settanni, L., Galati, A., Moschetti, G. and Francesca, N. (2017) Effect of the Lemon Essential Oils on the Safety and Sensory Quality of Salted Sardines (Sardina pilchardus Walbaum 1792). Food Control, 73, 1265-1274. https://doi.org/10.1016/j.foodcont.2016.10.046

[11] Al-Madhhachi, A.S., Al-Mussawy, H.A., Basheer, M.I. and Abdul-Sahib, A.A. (2020) Quantifying Tigris Riverbanks Stability of Southeast Baghdad City Using BSTEM. International Journal of Hydrology Science and Technology, 10, 230-247. https://doi.org/10.1504/IJHST.2020.107212

[12] Barradas, T.N. and Silva, K.G. (2020) Nanoemulsions as Optimized Vehicles for Essential Oils. In: Sustainable Agriculture Reviews 44, Springer, Cham, 115-167. https://doi.org/10.1007/978-3-030-41842-7 4

[13] Antonious, G.F., Turley, E., Mishra, B., Heist, Q., Upadhyaya, Y., Trivette, T. and Nkuwi, L. (2019) Characterization of Eggplant Grown in Animal Manure Amended Soil. International Journal of Environmental Health Research, 1-2. https://doi.org/10.1080/09603123.2019.1602252

[14] Calligaris, S., Manzocco, L., Valoppi, F., Comuzzo, P. and Nicoli, M.C. (2019) Microemulsions as Delivery Systems of Lemon Oil and $\beta$-Carotene into Beverages: Stability Test under Different Light Conditions. Journal of the Science of Food and Agriculture, 99, 7016-7020. https://doi.org/10.1002/jsfa.9973

[15] Chaisri, W., Chaiyana, W., Pikulkaew, S., Okonogi, S. and Suriyasathaporn, W. (2019) Enhancement of Acaricide Activity of Citronella Oil after Microemulsion Preparation. Japanese Journal of Veterinary Research, 67, 15-23. 
[16] Cortés, N.M., Califano, A.N. and Lorenzo, G. (2019) Physical and Chemical Stability under Environmental Stress of Microemulsions Formulated with Fish Oil. Food Research International, 119, 283-290. https://doi.org/10.1016/j.foodres.2019.01.067

[17] da Silva, M.R. and Ricci-Júnior, E. (2020) An Approach to Natural Insect Repellent Formulations: From Basic Research to Technological Development. Acta Tropica, Article ID: 105419. https://doi.org/10.1016/j.actatropica.2020.105419

[18] Das, S., Nanda, S.K., Rath, T., Prakash, K. and Bhattacharyay, D. (2020) In Silico Analysis of Phytochemicals from Lemon Grass against Shikimate Dehydrogenase of Staphylococcus aureus Causing Skin Disease. Plant Cell Biotechnology and Molecular Biology, 21, 51-55.

[19] Dávila-Rodríguez, M., López-Malo, A., Palou, E., Ramírez-Corona, N. and JiménezMunguía, M.T. (2020) Essential Oils Microemulsions Prepared with High-Frequency Ultrasound: Physical Properties and Antimicrobial Activity. Journal of Food Science and Technology. https://doi.org/10.1007/s13197-020-04449-8

[20] Deshmukh, K., Ahamed, M.B., Sadasivuni, K.K., Ponnamma, D., AlMaadeed, M.A., Pasha, S.K., Deshmukh, R.R. and Chidambaram, K. (2017) Graphene Oxide Reinforced Poly(4-styrenesulfonic acid)/polyvinyl Alcohol Blend Composites with Enhanced Dielectric Properties for Portable and Flexible Electronics. Materials Chemistry and Physics, 186, 188-201. https://doi.org/10.1016/j.matchemphys.2016.10.044

[21] Dong, J., Zhu, X.M., Wu, F.Y., Yang, B.Q., Feng, H., Dong, Y.F., Gu, W. and Chen, J. (2020) Development of Galangal Essential Oil-Based Microemulsion Gel for Transdermal Delivery of Flurbiprofen: Simultaneous Permeability Evaluation of Flurbiprofen and 1,8-Cineole. Drug Development and Industrial Pharmacy, 46, 91-100. https://doi.org/10.1080/03639045.2019.1706548

[22] Eid, R.K., Essa, E.A. and El Maghraby, G.M. (2019) Essential Oils in Niosomes for Enhanced Transdermal Delivery of Felodipine. Pharmaceutical Development and Technology, 24, 157-165. https://doi.org/10.1080/10837450.2018.1441302

[23] Flores-Villaseñor, S.E., Peralta-Rodríguez, R.D., Padilla-Vaca, F., Meléndez-Ortiz, H.I., Ramirez-Contreras, J.C. and Franco, B. (2019) Preparation of Peppermint Oil-Based Nanodevices Loaded with Paclitaxel: Cytotoxic and Apoptosis Studies in HeLa Cells. AAPS PharmSciTech, 20, 198.

https://doi.org/10.1208/s12249-019-1399-7

[24] Gandhi, J., Suthar, D., Patel, H., Shelat, P. and Parejiya, P. (2020) Development and Characterization of Microemulsion Based Topical Gel of Essential Oil of Clove ( $S y$ zygium aromaticum) for Superficial Fungal Infections. Advances in Traditional Medicine, 1-6. https://doi.org/10.1007/s13596-020-00462-6

[25] Gong, L., Liao, G., Luan, H., Chen, Q., Nie, X., Liu, D. and Feng, Y. (2020) Oil Solubilization in Sodium Dodecylbenzenesulfonate Micelles: New Insights into Surfactant Enhanced Oil Recovery. Journal of Colloid and Interface Science, 569, 219-228. https://doi.org/10.1016/j.jcis.2020.02.083

[26] Gulotta, A., Saberi, A.H., Nicoli, M.C. and McClements, D.J. (2014) Nanoemulsion-Based Delivery Systems for Polyunsaturated ( $\omega$-3) Oils: Formation Using a Spontaneous Emulsification Method. Journal of Agricultural and Food Chemistry, 62, 1720-1725. https://doi.org/10.1021/jf4054808

[27] Horincar, G., Enachi, E., Bolea, C., Râpeanu, G. and Aprodu, I. (2020) Value-Added Lager Beer Enriched with Eggplant (Solanum melongena L.) Peel Extract. Molecules, 25, 731. https://doi.org/10.3390/molecules25030731 
[28] Hussein, A., Abdel-Mottaleb, M.M., El-assal, M. and Sammour, O. (2020) Novel Biocompatible Essential Oil-Based Lipid Nanocapsules with Antifungal Properties. Journal of Drug Delivery Science and Technology, 56, Article ID: 101605. https://doi.org/10.1016/j.jddst.2020.101605

[29] Iqbal, N., Kumar, N., Agrawal, A. and Kumar, J. (2019) Development of Highly Stabilized Neem Oil Microemulsion System: A Green Approach. World Journal of Pharmaceutical Research, 8, 1507-1517.

[30] Koley, T.K., Tiwari, S.K., Sarkar, A., Nishad, J., Goswami, A. and Singh, B. (2019) Antioxidant Potential of Indian Eggplant: Comparison among White, Purple and Green Genotypes Using Chemometrics. Agricultural Research, 8, 9-20. https://doi.org/10.1007/s40003-018-0347-1

[31] Li, Y., Wang, C., Tao, Z., Zhao, Z., You, L., Zheng, R., Guo, X. and Zhang, Z. (2019) Enhanced Antioxidant and Antiproliferative Activities of Cymbopogon citrates (DC.) Stapf Essential Oils in Microemulsion. ACS Sustainable Chemistry \& Engineering, 7, 15173-15181. https://doi.org/10.1021/acssuschemeng.9b01606

[32] Li, Z., Xu, D., Yuan, Y., Wu, H., Hou, J., Kang, W. and Bai, B. (2020) Advances of Spontaneous Emulsification and Its Important Applications in Enhanced Oil Recovery Process. Advances in Colloid and Interface Science, 277, Article ID: 102119. https://doi.org/10.1016/j.cis.2020.102119

[33] Ling, J.L., Kormin, F., Abidin, N.A. and Anuar, N.A. (2019) Characterization and Stability Study of Lemongrass Oil Blend Microemulsion as Natural Preservative. IOP Conference Series: Earth and Environmental Science, 269, Article ID: 012026. https://doi.org/10.1088/1755-1315/269/1/012026

[34] Lourith, N., Kanlayavattanakul, M. and Ruktanonchai, U. (2016) Formulation and Stability of Moringa oleifera Oil Microemulsion. Soft Materials, 14, 64-71. https://doi.org/10.1080/1539445X.2016.1141786

[35] Lv, X., Cong, Z., Liu, Z., Ma, X., Xu, M., Tian, Y., Zhang, X., Xu, B., Zhang, J. and Tang, Z. (2018) Improvement of the Solubility, Photostability, Antioxidant Activity and UVB Photoprotection of Trans-Resveratrol by Essential Oil Based Microemulsions for Topical Application. Journal of Drug Delivery Science and Technology, 48, 346-354. https://doi.org/10.1016/j.jddst.2018.10.017

[36] Osanloo, M., Abdollahi, A., Valizadeh, A. and Abedinpour, N. (2020) Antibacterial Potential of Essential Oils of Zataria multiflora and Mentha piperita, Micro- and Nano-Formulated Forms. Iranian Journal of Microbiology, 12, 43. https://doi.org/10.18502/ijm.v12i1.2517

[37] Pavoni, L., Perinelli, D.R., Bonacucina, G., Cespi, M. and Palmieri, G.F. (2020) An Overview of Micro- and Nanoemulsions as Vehicles for Essential Oils: Formulation, Preparation and Stability. Nanomaterials, 10, 135. https://doi.org/10.3390/nano10010135

[38] Rao, J. and McClements, D.J. (2012) Food-Grade Microemulsions and Nanoemulsions: Role of Oil Phase Composition on Formation and Stability. Food Hydrocolloids, 29, 326-334. https://doi.org/10.1016/j.foodhyd.2012.04.008

[39] Sengar, A., Basheer, F., Aziz, A. and Farooqi, I.H. (2018) Aerobic Granulation Technology: Laboratory Studies to Full Scale Practices. Journal of Cleaner Production, 197, 616-632. https://doi.org/10.1016/j.jclepro.2018.06.167

[40] Rao, J. and McClements, D.J. (2011) Food-Grade Microemulsions, Nanoemulsions and Emulsions: Fabrication from Sucrose Monopalmitate \& Lemon Oil. Food Hydrocolloids, 25, 1413-1423. https://doi.org/10.1016/j.foodhyd.2011.02.004 
[41] Raveau, R., Fontaine, J. and Lounès-HadjSahraoui, A. (2020) Essential Oils as Potential Alternative Biocontrol Products against Plant Pathogens and Weeds: A Review. Foods, 9, 365. https://doi.org/10.3390/foods9030365

[42] Sakai, T., Seki, H., Yoshida, S., Hori, H., Suzuki, H., Nakamura, T. and Kawamura, I. (2019) Interaction of Clear Flavor Emulsions Containing Lemon Essential Oils with Lipid Bilayers via a Quartz Crystal Microbalance. Food Science and Technology Research, 25, 879-884. https://doi.org/10.3136/fstr.25.879

[43] Scorsatto, M., Pimentel, A.D., Silva, A.J., Sabally, K., Rosa, G. and Oliveira, G.M. (2017) Assessment of Bioactive Compounds, Physicochemical Composition, and in Vitro Antioxidant Activity of Eggplant Flour. International Journal of Cardiovascular Sciences, 30, 235-242. https://doi.org/10.5935/2359-4802.20170046

[44] Sharma, A., Dubey, S. and Iqbal, N. (2020) Microemulsion Formulation of Botanical Oils as an Efficient Tool to Provide Sustainable Agricultural Pest Management. In: Nano- and Micro-Encapsulation-Techniques and Applications, IntechOpen, London. https://doi.org/10.5772/intechopen.91788

[45] Singh, S., Singh, B. and Alam, T. (2019) Evaluation of Shelf-Life, Antioxidant Activity and Nutritional Quality Attributes in Carnauba Wax Coated Eggplant Genotypes. Journal of Food Science and Technology, 56, 4826-4833. https://doi.org/10.1007/s13197-019-03944-x

[46] Su, D. and Zhong, Q. (2016) Lemon Oil Nanoemulsions Fabricated with Sodium Caseinate and Tween 20 Using Phase Inversion Temperature Method. Journal of Food Engineering, 171, 214-221. https://doi.org/10.1016/j.jfoodeng.2015.10.040

[47] Sumonsiri, N., Danpongprasert, W. and Thaidech, K. (2020) Comparison of Sweet Orange (Citrus sinensis) and Lemon (Citrus limonum) Essential Oils on Qualities of Fresh-Cut Apples during Storage. Scientific Study \& Research. Chemistry \& Chemical Engineering, Biotechnology, Food Industry, 21, 47-57.

[48] Tanzeem, M.U., Asghar, S., Khalid, S.H., Asif, M., Ullah, M.S., Khan, I.U., Khalid, I., Faran, S.A., Rehman, A., Gohar, U.F. and Hussain, T. (2019) Clove Oil-Based Co-Surfactant Free Microemulsion of Flurbiprofen: Improved Solubility with Ameliorated Drug-Induced Gastritis. Pakistan Journal of Pharmaceutical Sciences, 32, 2787-2793.

[49] Valoppi, F., Frisina, R. and Calligaris, S. (2017) Fabrication of Transparent Lemon Oil Loaded Microemulsions by Phase Inversion Temperature (PIT) Method: Effect of Oil Phase Composition and Stability after Dilution. Food Biophysics, 12, 244-249. https://doi.org/10.1007/s11483-017-9480-9 